OPEN ACCESS

Edited by: Michail Mantzios, Birmingham City University, United Kingdom

Reviewed by: Rebecca Keyte Birmingham City University, United Kingdom Seema Puri

University of Delhi, India

*Correspondence: Lyn Lampmann l.lampmann@posteo.de

Specialty section:

This article was submitted to Eating Behavior

a section of the journal Frontiers in Nutrition

Received: 04 June 2021 Accepted: 12 August 2021 Published: 14 September 2021

Citation:

Lampmann L, Emberger-Klein A and Menrad K (2021) Determining the Distinguishing Features of Different Eating Action Types in Germany Using a Mixed-Method Approach.

Front. Nutr. 8:720392.

doi: 10.3389/fnut.2021.720392

\section{Determining the Distinguishing Features of Different Eating Action Types in Germany Using a Mixed-Method Approach}

\author{
Lyn Lampmann*, Agnes Emberger-Klein and Klaus Menrad
}

Chair of Marketing and Management of Biogenic Resources, Weihenstephan-Triesdorf University of Applied Sciences, Technical University of Munich Straubing for Biotechnology and Sustainability, Straubing, Germany

Food-related behavior is a very complex topic, as it affects the most diverse areas of life. Accordingly, wide varieties of disciplines have already dealt with the topic to understand it better. The result is that there is neither a uniform nutrition knowledge nor a uniform nutrition behavior. In order to reduce the complexity of a field of study, there is the methodical means of type-building. Both commercial and academic studies have already formed nutrition types, either by means of standardized questionnaires or with a specific content focus. However, since both individual and social aspects influence food-related behavior, we investigate how people integrate eating into their everyday life against the background of (competing) individual and social demands by focusing on the individual point of view, for which a mixed methods approach is used. Based on 42 semi-structured, problem-centered interviews conducted in Germany in 2017, we built qualitative food-related types in a first step, which are analyzed in this article using a quantitative content analysis and cross-over analysis to identify the particular distinguishing feature(s) of each type and test them for significance. The results show the prominent characteristics for each type and indicate furthermore that subjectivization, self-determination, the body as an instrument of power, adaptation to the environment and being overstrained with the own behavior are particularly prominent when it comes to eating. Moreover, we clearly identified The Overstrained and The Relaxed as independent eating action types, which we could not find anywhere else. The study shows that interventions, especially for The Overstrained and The Controlled, are necessary to achieve a relaxed approach to eating in everyday life. At the same time, systematic approaches should be used to intervene in cases of overstraining or controlled behavior.

Keywords: eating action type, data transformation, quantitative content analysis, cross-over analysis, mixed-methods

\section{INTRODUCTION}

"Food is so important, and permeates human life in so many ways, that it engages and interacts with almost all of our activities: leisure, the art, sex, work..." (1). The fact that so many areas of daily life can be influenced by food-related behavior has led to different nutritional approaches and views, with neither uniform nor coherent nutritional knowledge nor behavior $(2,3)$, making it a very complex issue (4-6). Relevant nutritional approaches include food choice approaches [e.g., (7-9)], 
practice theory approaches [e.g., (6, 10)], psychological approaches [e.g., $(11,12)]$ and approaches that look at pure physiological food intake [e.g., (13)].

In order to reduce the complexity of a field of study, types can be built. In this process, subjects or objects of an area of study are classified by means of grouping processes based on previously defined characteristics (14). Thus, type-building (1517) sorts facts according to comparable characteristics (such as e.g., attitudes toward organic food, sports behavior, or the behavior of individuals in group work, etc.) (18). The aim of type-building is to reduce the diversity of data to a few workable and meaningful terms (15) and thus reduce the complexity of situational or personal constructs (19). This approach can be implemented using qualitative methods as well as quantitative methods. In quantitative research types can be built, e.g., via cluster analysis procedures (15), and in qualitative research, e.g., via type-building methods according to Kuckartz (20).

In Germany, many of the existing nutrition types have been developed by commercial market research institutes (2125) mainly to explain food demand of differing consumer groups. Generally, these nutrition types are rather heterogenic and the applied methods how they have been built often do not lay open. Nonetheless, these institutes normally apply multivariate statistical methods that examine the consumers regarding their differences or similarities (26). One well-known example are the seven Nestlé nutrition types (25). Based on the nutritional attitudes of the respondents, Nestle found The Passionless Pragmatists, The Problem Conscious, The Carefree Full Eaters, The Hunted, The Health Idealists, The Nest Warmer and The Modern Multi-Optional (25). The results showed that the nutrition culture is becoming more and more heterogeneous, but many people are basically pursuing a specific goal with their diet: Fitness, health, personal well-being, self-optimisation or personal appearance (27). In 2012, the Rheingold-Institute has come up with 10 nutrition types. Amongst the results were types called Mr. and Mrs. Right, Salad Singles, Machines or Food Poser (22). The built types are each associated with a lifestyle, assuming that culinary preferences reflect the lifestyle of the consumer (22). The GfK built eight cooking types, based on the purchasing behavior of the households. The built types have names like The HighClass Cook, The Everyday Cook, The Weekend Cook, The Warmer and The Out-Of-Home Eater (23). This study provided insight into the changes taking place in the kitchen due to changing role models and the changing working day, assuming furthermore that the development of cooking and eating at home changes the demand for food (23). Additionally, Nielsen Holdings plc published in 2017 seven nutrition types built by requesting 10.000 subjects about their dietary habits, the underlying reasons and the belonging trigger (21). However, one learns very little about the study itself and its purpose.

In addition to the nutrition types of the commercial market research institutes, such nutrition types also were built in Germany in several scientific studies (28-31). With the aim of investigating whether cross-national food consumers can be found, Brunsø et al. (29) developed the food-related lifestyle and defined it as a system of cognitive categories, which were related to different dimensions of nutrition. Based on a survey instrument consisting of 23 sub-dimensions focusing on purchasing behavior, cooking methods, quality aspects, consumption situations and purchasing motives they found five consumer groups in Germany: The Uninvolved, The Careless, The Conservative, The Rational, and The Adventurous (29). The results suggest a relatively strong trend toward cross-national segments. Nevertheless, different strategies need to be developed for the different target groups to target them with products and get them to buy (29).

Bruhn (28) developed a Lifestyle Decision Typology of Nutritional Behavior resulting in four nutrition types (e.g., The Disinterested Consumer, The Traditional Consumer etc.). By applying the food-related lifestyle (FRL), a subsequent cluster analysis and a survey of the dietary behavior, the respondents were segmented according to their lifestyle for food and its significance for health-conscious eating habits (28). The aim was to contribute to behavioral prevention measures in the context of a growing obesity rate. Some possibilities for intervention are pointed out. For example, in addition to promoting healthconscious choices through nutrition education and information, a supportive environment should be created, for example through legislative initiatives, as this is considered the best way to change behavior in the long term (28).

Kluß (30) analyzed the meaning of pleasure, the ability to enjoy and the enjoyment orientation and found e.g., types named: The Pleasure-Oriented or the Rational. The study was based on a qualitative study and evaluated secondary analytical 26 guidelinebased interviews. The interviews dealt with attitudes toward nutrition, eating habits and situations analysis (30). Against the background of the heterogeneity of young people living in an affluent society, this study has shown that education as a resource can be an important factor in consciously dealing with the own eating pleasure and learning how to deal with it (30). In contrast, Stieß and Hayn (31) focused on the nutritional action in everyday life of the respondents to develop strategies that promote a sustainable nutrition. The aim was to illustrate action options and latitudes of the consumers in the context of environment, nutrition and health and their claims toward a sustainable and healthy nutrition. Seven nutrition styles were built, such as The Disinterested Fast-Fooder or The Cheap and Meat Eaters, based on the purchasing, cooking or comprehensive nutrition orientation and sociodemographic information. The analysis was based on a two-stage empirical survey that started with a qualitative phase and was followed by a quantitative survey (31). The results showed that the change in everyday nutrition leads to a variety of different patterns of action, for example by shifting the main meal to the evening or having a big breakfast together on Sunday (31).

Summarizing, the presented academic typologies focused on a specific topic within food-related behavior such as e.g., sustainability, pleasure or obesity while the commercial studies mainly aimed to explain food demand or nutrition behavior of differing consumer groups. Such insights can be used for commercial as well as policy-driven activities. The first group includes developing differing food products for heterogeneous consumer groups, adapting business and marketing strategies to differing needs of consumers or elaborating adapted information and communication strategies for such purposes. Policy-driven 
activities that use the insights of typology or segmentation studies include e.g., regulatory initiatives but also information, education or communication campaigns to support e.g., a more healthy food choice in particular of vulnerable groups of the population.

In contrast to the aforementioned commercial as well as academic food-related behavior typologies, we pay special attention to food-related behavior from the individual's point of view and aiming at considering the multiple aspects of how people integrate eating into their everyday lives, while engaging with themselves and their environment $(32,33)$. The focus is therefore clearly on the individual and his or her challenge to develop the own personality in everyday life and to socialize at the same time $(32,33)$. Since eating is a very everyday phenomenon that is carried out several times a day alone or with others (12), it is understood as part of this engagement with oneself and the environment, to adapt or to distinguish oneself (11).

For this purpose, the idea of qualitative social research fits best, since it sheds light on the subject and on the indepth understanding of its actions $(34,35)$. The application of qualitative interviews was thus ideally suited for the purpose to build a typology.

However, as both research methods, qualitative and quantitative, have their justification and their individual advantages, which mutually benefit each other $(36,37)$, we decided to apply a mixed methods design for the analysis of the previously built types. Using mixed methods involves collecting and integrating both qualitative and quantitative data to enable analysis of the strengths of both approaches (36).

Therefore, as a first step, we focused in a previous study on how people integrated eating into their everyday lives while engaging with themselves and the environment, thus living out personality development and related socialization (33). The aim was to build types using type-building qualitative content analysis (20) and following Spiekermann's (38) definition of eating action ["Esshandeln," (38)], which implies action as well as interpretations processes of self-thinking individuals. This enabled us to build seven eating action types.

In this article, following the first step, we apply quantitative research methods as a mixed-methods approach to the analysis of the seven eating action types using cross over analysis and a quantitative content analysis of communication. We aim to gain breadth and depth in understanding and corroboration (39) of the different types. Thus, the unique feature(s) of each type shall be determined and a better understanding of the various food-related behaviors shall be created. By means of statistical analysis procedures, the special characteristics of the respective types can also tested for their significance. This allows an even deeper insight into those aspects that play a special role for and in the integration of eating into everyday life by emphasizing the differences in food-related behavior of German consumers. Thus, the target of this study is to analyze how people integrate eating into their everyday lives, while engaging with themselves and their environment in Germany, using a mixed-methods approach.

This article is a first step toward generalizing the results of the qualitatively built eating action type, using a mixed-method approach that widens the methodological instrumental set in this field of food-related behavior. It can be understood as a "precursor" to the derivation of a general typology that does not have a thematic focus but refers to the population as a whole by focusing on the integration of eating into everyday life and the challenges, their effects and ways of dealing with them from the perspective of the individual.

The results of this study are valuable for nutrition consultancies, food companies, politicians and advisers in order to consider people's differing ways how to integrate eating in their daily lives in their specific activities. This might improve business success of commercial companies, but also enhance effectiveness of political initiatives and advice and education activities in the field of nutrition and eating.

\section{METHODOLOGY \\ Design Overview}

In 2017, we conducted 42 semi-structured, problem-centered interviews in Bavaria, Germany. Interviews were conducted at the (Self-identifying Institution) in the city of (Self-identifying city), at the Institute for (Self-identifying Institution) in (Selfidentifying city) or at the respondents' homes either in the city of (Self-identifying city) or in the city of (Self-identifying city). Participants were contacted via a university email distribution list, a recruitment call in local newspapers or via a list of participants from previous studies.

The interviews focused on how people integrate eating in their everyday lives from their personal point of view (40) and by that living out personality development and related socialization $(32,33)$.

The interview guideline was developed after reviewing relevant literature on food-related types. It consisted of six sections, two of which are not relevant to this article: 1 . the introduction including informed consent, 3. a section on foodrelated behavior including a 24 -h recall and a problem-centered interview about the previous eating day and the last Sunday, 5. a short questionnaire on socio-demographic characteristics, and 6. a conclusion. The interview guideline was pre-tested twice and slightly adapted. All interviews were tape-recorded except for one where notes were taken $(35,41)$.

The questions of the problem-centered interview took into account the two dimensions of the eating action approach, the action as well as interpretation processes, the extent of which was analyzed for each type (40). These were questions about the food consumed, purchasing and cooking behavior, the design of eating situations, and snacking behavior to capture the action processes. Questions about the importance that eating takes in everyday life, the emotions associated with eating, the importance of eating in society and about inner conflicts regarding eating covered the interpretation processes.

The interviews were tape-recorded and transcribed verbatim. However, all data were anonymised to ensure that participants were not identifiable by the information they gave.

In addition to the interviews, we collected quantitative data using a standardized questionnaire, in which participants were asked to state their gender, age and weight. 
All participants gave informed written consent and their participation was voluntary. Ethical approval was not required because we did not collect any sensitive personal data from the participants and did not conduct a medical study. The data protection officer (of self-identifying institution) approved the privacy statement and the documentation of the procedure. We adhered to the established and recorded ethical principles of the Declaration of Helsinki, the German Research Foundation (DFG) and the German Sociological Association (DGS) throughout the study to ensure appropriate conduct.

\section{Description of Sampling}

The aim of the sampling was to obtain a relatively heterogeneous group in terms of the participants' age and gender. Initially, the only criterion for inclusion in the study was a minimum age of 18 years, as parental consent would have been required for younger participants. However, only 37 of the 42 interviews were selected for the analysis. The others were rejected due to two incomplete worksheets, one case of unsuitable responses, one different nationality and one case of an eating disorder. For reasons of comparability, after conducting the interviews we decided not to consider the last two cases for the study either. Nevertheless, saturation was achieved, as no new subjects were identified in the interviews, as confirmed by the data analysis (42). None of those invited to take part refused to participate in the interview. All participants were paid $€ 15$ for their assistance. The age range of the respondents was between 18 and 83 years. The study was carried out with 19 men and 18 women. Twentysix people were of normal weight, eight were pre-obese and three were obese (43). All participants were born in Germany and had been socialized in Western European culture. Three participants were vegans (all female), another three were vegetarians (one male, two female) and the remaining 31 were omnivores. For the sociodemographic characteristics, please see Table 1.

\section{Data Analysis: Qualitative Content Analysis}

The first author was the key person for coding and analysis of the collected information.

To analyze the qualitative interviews, we employed contentstructuring qualitative analysis as described by Kuckartz (20) as a first analytical step. This form of analysis aims to identify topics and sub-topics and their systematization and conceptualization. We have worked with the deductive-inductive approach (20), whereby following the guideline, existing (deductive) as well as new (inductive) thematic (close to the material) and analytical (conceptualizing, abstracting) categories were generated and identified (20). Then we wrote case summaries for each interview. In doing so, we worked fact-oriented and close to the text from the perspective of the research question (20).

Afterwards, we performed type-building content analysis (20). This procedure describes a methodological controlled analysis, at which a typology is the result of a grouping process, where a certain social condition is divided into types by means of one or more features. This form of analysis method is particularly useful when qualitative data is available. Moreover, the procedure is described in a comprehensible way and does not fail due to a too high level of abstraction. As a result, the elements of one type are as similar as possible (internal homogeneity), but as different as possible compared to other types (external heterogeneity) $(20,44)$. To build the typology, we worked as a team. For this purpose, the case summaries were distributed fairly among five independent researchers, who in turn had to summarize the case studies in key words according to the two dimensions of the eating action approach. In two team meetings, the group members presented their cases, in terms of the important features and pinned them on a pin board-either next to or away from the already presented, similar or different cases. The group constantly discussed the results. Through this process, certain groups emerged (20). The result was a rough structure of a typology. The next step was to free the resulting types from their assigned cases. Subsequently, three persons from the teamwork, including the first and second authors, differentiated the emerged types. Thereafter, the cases were assigned to the types again (45). The aim was to construct polythetic types, i.e., cases belonging to a type are as similar as possible, but do not have to be identical (20). Moreover, the results are real types (45). All types built are constructs from model cases. For this purpose, relevant text segments from different cases were selected according to the criterion of plausibility for the type to be described and combined for the description (20).

As can be seen in Table 2, the following seven eating action types are the result of that process: Eating as a way of life, The Relaxed, Eating as self-determination, Eating as a necessary Evil, The Adaptive, The Overstrained and The Controlled.

\section{Quantitative Content Analysis and Cross-Over Analysis}

For the purpose of this study, we conducted a quantitative content analysis with the interviews in a second step, since it is 'a research technique for the systematic, objective, and quantitative description of the manifest content of communication' (54). Thus, it can be used to describe the surface content of communication (55). The benefit of this approach is that it gives an insight into the factors that influence individuals in the seven eating action types without having to enquire directly about personal food-related issues and thus run the risk of receiving answers based on the principle of social desirability (12).

We also analyzed the eating action types using crossover analysis to gain a deeper insight of both the essential similarities and differences (56) between the types in terms of their unique features. We applied cross-over analysis based on the quantification of the qualitative variables resulting from qualitative content analysis. This approach is defined as the procedure in which at least one analysis type of one tradition (qualitative/quantitative data) is applied in order to analyze the data of the other tradition (57). It is therefore an inter-paradigmatic analysis (58). Cross-over analysis is especially useful for analyzing complementarity and elucidating (in-)consistencies (59, 60). It is understood in terms of convergent design, which collects and analyses quantitative and qualitative data at similar points in time and is followed by integrated analysis (36). We focused on data 
TABLE 1 | Overview of the contents of the seven eating action types (40).

\begin{tabular}{|c|c|c|}
\hline $\begin{array}{l}\text { Eating action } \\
\text { type }\end{array}$ & Short descreption of eating action & Essential quote \\
\hline $\begin{array}{l}\text { Eating as a way of } \\
\text { life } \\
(n=3)\end{array}$ & $\begin{array}{l}\text { Characterized by a uniform food concept, } \\
\text { such as veganism or a diet based mainly on } \\
\text { (wild) herbs. These concepts steer one's own } \\
\text { nutritional behavior in a certain direction, } \\
\text { which is determined by self-imposed rules } \\
\text { and demands out of conviction and which } \\
\text { have an impact on the general lifestyle; }\end{array}$ & $\begin{array}{l}\text { So the last few years I have been VERY } \\
\text { busy with it, but I am now putting this } \\
\text { knowledge into practice. That's why I don't } \\
\text { read so much in books anymore, because I } \\
\text { have the knowledge now and integrate it } \\
\text { into my everyday life or shopping. }\end{array}$ \\
\hline
\end{tabular}

have an impact on the general lifestyle;

however, the chosen concept remains entirely endorsed.

The Relaxed

$(n=7)$

Characterized by a conscious and relaxed relationship with their own food-related behavior and the ideas implied. The implementation of the ideas works without effort. Food is strongly associated with positive emotions such as pleasure, joy and anticipation.

Eating as a way of Nutrition is given a high priority, as it is self-determination understood as a means of implementing and $(N=7)$

Eating as a necessary evil $(N=3)$

The Adaptive $(N=5)$

The Overstrained $(N=8)$

The Controlled $(N=4)$ center of attention and the own needs and demands receive special attention. The need to be free in one's own decisions is high. However, this type does not follow a unified concept such as veganism, but develops its own food concepts, which in particular include the demand for healthy eating.

Food and everything that belongs to it is of little importance. It is rather understood as something necessary for life. Therefore, little thought is given to food, eating and the behavior associated with it.

Adaptation to others is the characteristic feature of this type. Therefore, the food-related behavior is not implemented independently. Rather, they wait for others to become active in terms of food and they just have to join in. Accordingly, eating together with other (close) people is of special attention.

Characterized by overstraining with food. Overstraining results either from personal overload or from external circumstances such as unemployment or illness. Individuals debate with themselves what and how to do things properly, but do not reach a good solution. This leads to behavior patterns, which they do not feel comfortable with and which further unsettle them.

Characteristic for this type is the compulsion to keep control over one's own body. This strong need is seen as a unique and particularly characteristic feature of this type, as it determines all food-related behavior. understood as a means of implementing and
satisfying one's own needs. The self is at the pressure and thirdly because I believe that I what's in it. Well, that is also important for
Possible explanation

Spiritualising food and the body through alternative eating. Thus, victory of the mind over the body (11).

I feel good and comfortable with [the meal], firstly because I know that I enjoyed it, secondly because I had time, that I could enjoy it, that I wasn't under any time also fed myself well and correctly and varied.

But I still always look forward to my salad for lunch. [...] especially because I know that it is homemade and because I know me. I feel much better when I eat my salad than a meatloaf bread roll I bought at work.

Dijker (46) explains the ability of a moderate eating style, which is characterized by perception, consciousness and motivation, representing elements that can all be found in this type.

In self-determination theory (SDT), action can be taken according to autonomous motivation $(47,48)$, whereby food-related behavior is understood as an opportunity for self-determination and the associated well-being $(47,48)$.

So [eating] is necessary for the preservation Age plays an important role here, as age brings with it of life, but there is no fun in it. I cannot say. an increased risk of a lack of social interaction, which is particularly evident during meals (49). This can lead to loneliness. For this reason, these people attach particular importance to their remaining social relationships and rate food as secondary.

Okay, and that's where I adapt. [...] on According to Chernyakova (50), the preservation of weekends [...] the only son who still lives in identity in the course of adaptation, the perception of [..] comes with his wife and one of my adaptation as a desired action and the existence of grandchildren [...] and they bring, I pay, but appropriate circumstances that enable the subject to they bring the food. Therefore, they make the necessary changes are essential aspects of determine [...]. social and successful adaptation. Accordingly, adaptation reflects behavior that goes along with well-being while preserving one's own identity.

And sometimes it's stress because when I It can be assumed that the overstraining is influenced can't decide what I want, it stresses me. by a discrepancy between implicit and explicit motives. Especially before shopping, because I always think about what I have to buy or what I want to buy and that's a mixture of I'm actually happy that I can buy everything I want, because I don't have anything at home and on the other hand it's like: buy the RIGHT one too. Job et al. (51) showed that motivational discrepancy is related to emotional distress, while emotional distress is (partly) responsible for the connection between motivational discrepancy and food-related behavior. People with motivational discrepancy eat more and prefer unhealthy, tasty food because they want to downregulate the emotional stress caused by the motivational discrepancy (51). The Overstrained repeatedly emphasized the discrepancy between internal values, ideas and wishes and external circumstances and demands.

But even if I'm hungry, I still don't eat. Because I always pay attention to my kilos. But I actually like doing it [eating] very much.

Sociological theories of action assume that the body is a controllable instrument that is subject to the will of man $(52,53)$. Body modifications are associated with success, because athletic bodies represent positively connoted social norms such as performance, endurance and strength (52). 
TABLE 2 | Typology table - sociodemographic characteristics, weight and nutrition of eating action types.

\begin{tabular}{|c|c|c|c|c|c|c|c|}
\hline Variable & $\begin{array}{l}\text { Eating as a } \\
\text { way of life } \\
(N=3)\end{array}$ & $\begin{array}{l}\text { The Relaxed } \\
\qquad(N=7)\end{array}$ & $\begin{array}{l}\text { Eating as a way of } \\
\text { self-determination } \\
\qquad(N=7)\end{array}$ & $\begin{array}{l}\text { Eating as a } \\
\text { necessary } \\
\text { evil }(N=3)\end{array}$ & $\begin{array}{c}\text { The } \\
\text { Adaptive } \\
(N=5)\end{array}$ & $\begin{array}{c}\text { The } \\
\text { Overstrained } \\
(N=8)\end{array}$ & $\begin{array}{c}\text { The } \\
\text { Controlled } \\
(N=4)\end{array}$ \\
\hline Gender: male, number (\%) & $1(33.3)$ & $3(42.9)$ & $2(28.6)$ & $1(33.3)$ & $4(80.0)$ & $6(75.0)$ & $2(50.0)$ \\
\hline $\begin{array}{l}\text { Age, mean value (standard } \\
\text { deviation) }\end{array}$ & $42.3(18.4)$ & $42.9(24.0)$ & 38.7 (23.3) & $81.7(1.2)$ & $55.4(22.4)$ & $53.8(20.9)$ & $45.8(14.0)$ \\
\hline Overweight, number (\%) & 0 & $1(14.3)$ & $1(14.3)$ & $2(66.7)$ & $1(20.0)$ & $2(25.0)$ & $1(25.0)$ \\
\hline Regular weight, number (\%) & $3(100.0)$ & $5(71.4)$ & $6(85.7)$ & $1(33.3)$ & $3(60.0)$ & $5(62.5)$ & $3(75.0)$ \\
\hline$N=$ Number of individuals of & $3(8.1 \%)$ & 7 (18.9\%) & 7 (18.9\%) & $3(8.1 \%)$ & $5(13.5 \%)$ & $8(21.6 \%)$ & $4(10.8 \%)$ \\
\hline
\end{tabular}

the total sample

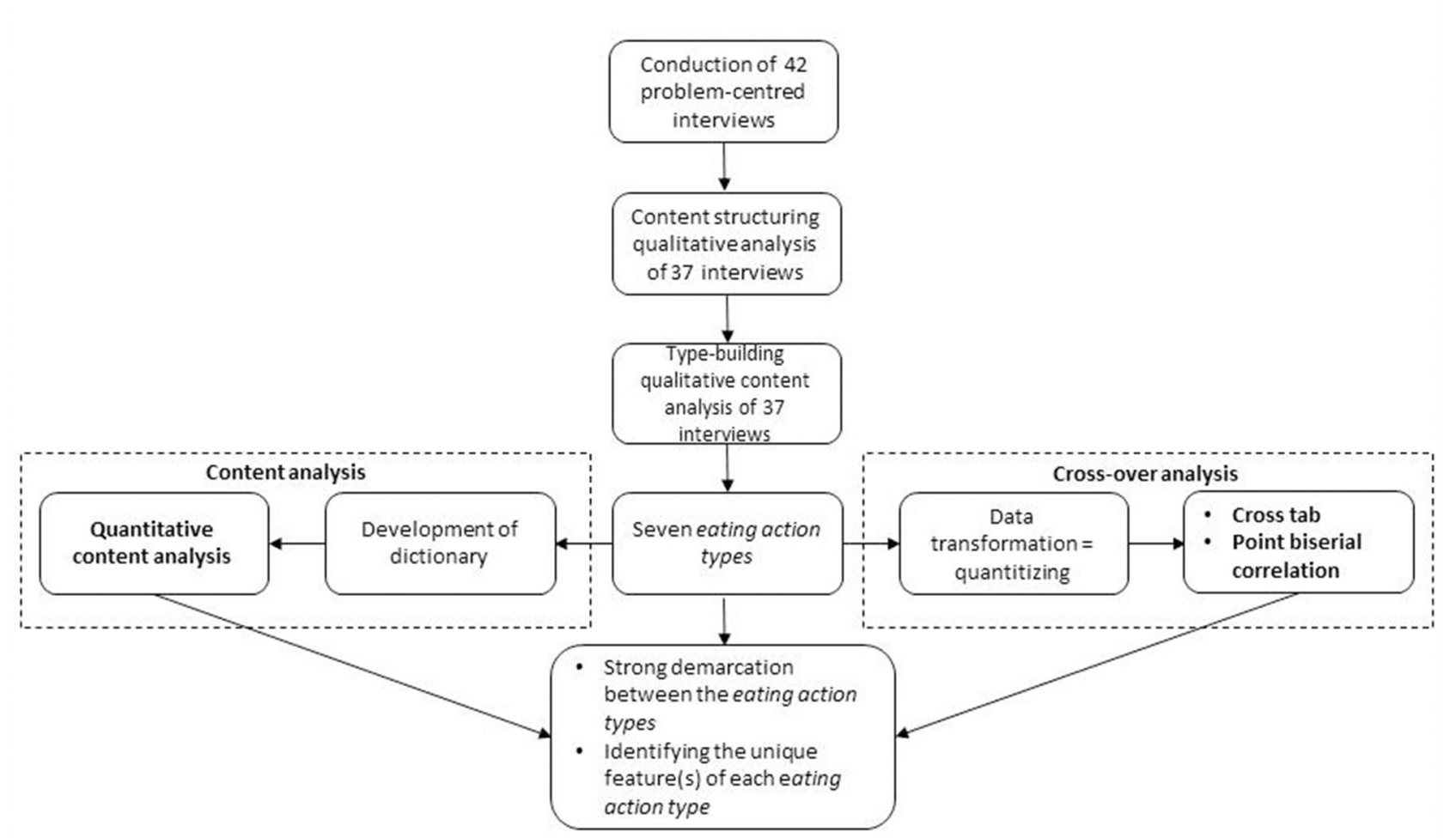

FIGURE 1 | Data collection and study design.

transformation as an analysis strategy for complementarity. Data transformation is the conversion of one type of data into another (61). Interpretability is best enhanced when the methods are implemented simultaneously and interactively within a single study (59). Our analysis mainly collected qualitative data, some of which was converted into quantitative data ("quantitizing") (62) in order to detect regularities and unique features in the qualitative data that would otherwise not be recognizable or communicable (63). Next, the data was analyzed and integrated. The aim was to corroborate the results ("corroboration"), to obtain complementary information on phenomena ("complementarity") and to expand the information spectrum (“completeness") $(64,65)$.

For a detailed overview of the study design applied, please see Figure 1.

\section{Data Analysis: Mixed Methods}

As a basis for our quantitative content analysis, we created a "go list." For the "go-list," the MAXQDA (66) software, which included all transcribed interviews, was used to look at the most frequently mentioned words of each eating action type. However, only meaningful words were taken into account, i.e., words that have a certain content and a value, such as "pleasant," "sin," 
TABLE 3 | Results of the quantitative content analysis based on categories.

\begin{tabular}{|c|c|c|c|c|c|c|c|}
\hline Dimension & $\begin{array}{l}\text { Eating as a } \\
\text { way of life } \\
(N=3)\end{array}$ & $\begin{array}{l}\text { The Relaxed } \\
\qquad(N=7)\end{array}$ & $\begin{array}{c}\text { Eating as } \\
\text { self-determination } \\
(N=7)\end{array}$ & $\begin{array}{c}\text { Eating as a } \\
\text { necessary evil } \\
(N=3)\end{array}$ & $\begin{array}{l}\text { The Adaptive } \\
\qquad(N=5)\end{array}$ & $\begin{array}{c}\text { The } \\
\text { Overstrained } \\
(N=8)\end{array}$ & $\begin{array}{l}\text { The Controlled } \\
\qquad(N=4)\end{array}$ \\
\hline $\begin{array}{l}\text { Most frequent } \\
\text { content }\end{array}$ & $\begin{array}{l}\text { Body reference } \\
(18)^{\star}\end{array}$ & $\begin{array}{l}\text { Body reference } \\
\text { (16) }\end{array}$ & Intended behavior (21) & Habits (5) & Community (9) & $\begin{array}{l}\text { Body reference } \\
\text { (20) }\end{array}$ & $\begin{array}{l}\text { Body reference } \\
\text { (20) }\end{array}$ \\
\hline $\begin{array}{l}\text { Second-most } \\
\text { frequent content }\end{array}$ & $\begin{array}{l}\text { Subjectivization } \\
(10)\end{array}$ & Community (15) & Community (18) & & Habits (7) & $\begin{array}{c}\text { Intended } \\
\text { behavior (17) }\end{array}$ & $\begin{array}{c}\text { Control behavior } \\
\text { (16) }\end{array}$ \\
\hline
\end{tabular}

*Number in brackets: counted citations.

"indulge," "gratitude," or "enjoyment," and which are not devoid of content, such as the constantly used word "I," but also "as" or "how," which are much more frequent in their pure occurrence. In order to ensure that the meaning of the relevant words was related to food, the context was examined in which the word was used. If there was no food reference, this passage was removed manually so that it was not counted as an instance of the word occurring. Thus, the aim of the "go-list" was to identify foodrelated content and evaluations that were frequently mentioned and thus were particularly characteristic for each type.

Next, we developed a dictionary based on the words included from the "go-list," using a special function of the MAXQDA software, to create groups of words similar in content and to develop categories by assigning descriptive names to each group. Based on this category system, a quantitative content analysis was performed. In this process, we used the list of references from the respective text passage in the interview and checked whether the statements made by the participants actually reflected the category counted. This procedure was repeated several times until the quantitative content analysis based on the dictionary no longer gave misleading results.

Initially, our dictionary contained 13 categories. However, we excluded four categories, because they contained too few words compared to the other categories. Thus, all categories contain a minimum of seven words. If a word belonging to a certain category was mentioned several times in a single sentence, we only counted that category once.

In addition, we performed a cross tab analysis of the eating action types and the categories that evolved in the course of the qualitative content analysis.

We complemented and checked the results of the cross tab by evaluating the point biserial correlation using SPSS (67). The point biserial correlation is particularly suited to the analysis of relationships between an interval-scaled variable (number of counts of the categories) and a dichotomous variable (eating action type) (68). We quantified the main categories and subcategories of the qualitative content analysis by transforming them into numeric variables (number of mentions) using MAXQDA.

\section{RESULTS}

This section presents the main findings of the analysis in the form of a single paragraph summary for each eating action type.

Table 3 shows the results of the quantitative content analysis for each eating action type. The most frequent content is "body reference." It should be noted, however, that seemingly identical content can have quite different origins and consequences. For example, in The Relaxed "body reference" stands for the need to be full and well-fed, whereof in The Overstrained it stands for the physical discomfort triggered by the own food-related behavior, which is perceived as not being good. Despite these differences in content, both types emphasize the relevance of body sensations.

In order to determine the unique features of each eating action type, we have listed the important qualitative categories identified for the types in Table 4. However, behavior can vary among individuals of the same type. Thus, the qualitative categories in Table 4 do not necessarily apply to every individual to the same extent. For example, Table 4 shows that for Eating as a way of life the behavior change was through information acquisition, which cannot be found for any other eating action type. The same is true for The Adaptive, where eating is a very important part of family life and is also unique in comparison.

To analyze which qualitative categories are able to withstand statistical calculation and are thus significant and indicative for each type, we have calculated the point biserial correlations for each category and each eating action type, which are shown in Table 5. The values highlighted in bold are significant values calculated by the point biserial correlation.

Again, an example of a highly significant correlation is the behavioral change through information acquisition in Eating as a way of life. Also highly significant is the overstraining and the negative affect toward the own food-related behavior of The Overstrained. Another significant value is the compensatory behavior of The Controlled, which is used, for example, by skipping meals in order to compensate for previous meals in their effect on the body.

It is also worth mentioning that five significant values could be calculated from the quantitative content analysis for Eating as a way of life, but only one for Eating as necessary Evil, i.e., for the group for whom food is simply not of great importance.

Finally, we have combined the results of our study in Table 6. In the following, we will go into more detail about the findings shown in Table 6. Above all, this table shows how the individual eating action types are reflected in actual unique features.

\section{Eating as a Way of Life}

This type is represented by two women and one man. All three are of regular weight. It is the eating action type with the secondlowest age, with an average of 42.3 years.

Eating as a way of life is characterized by a unified and lifeinfluencing nutritional idea. Thus, the lifestyle, which implies an idea of an ideal diet, is oriented toward one's own demands and needs, i.e., living in harmony with nature, the body and 
TABLE 4 | Cross table for selected categories based on qualitative content analysis: percentage of number $N=$ individuals.

\begin{tabular}{|c|c|c|c|c|c|c|c|}
\hline Category & $\begin{array}{l}\text { Eating as a } \\
\text { way of life } \\
\qquad(N=3)\end{array}$ & $\begin{array}{l}\text { The Relaxed } \\
\qquad(N=7)\end{array}$ & $\begin{array}{c}\text { Eating as } \\
\text { self-determination } \\
(N=7)\end{array}$ & $\begin{array}{c}\text { Eating as a } \\
\text { necessary evil } \\
(N=3)\end{array}$ & $\begin{array}{c}\text { The } \\
\text { Adaptive } \\
(N=5)\end{array}$ & $\begin{array}{c}\text { The } \\
\text { Overstrained } \\
(N=8)\end{array}$ & $\begin{array}{c}\text { The } \\
\text { Controlled } \\
(N=4)\end{array}$ \\
\hline $\begin{array}{l}\text { Behavioral change by gathering of } \\
\text { information }\end{array}$ & 100.00 & 0.00 & 0.00 & 0.00 & 0.00 & 0.00 & 25.00 \\
\hline Dealing with own demands & 66.67 & 0.00 & 0.00 & 0.00 & 0.00 & 25.00 & 0.00 \\
\hline Rewarding & 66.67 & 14.29 & 14.29 & 0.00 & 0.00 & 25.00 & 0.00 \\
\hline Relating to others & 100.00 & 0.00 & 28.57 & 0.00 & 0.00 & 25.00 & 50.00 \\
\hline Belief in natural physical needs & 66.67 & 14.29 & 14.29 & 0.00 & 0.00 & 0.00 & 100.00 \\
\hline $\begin{array}{l}\text { Reasoning of own consumption } \\
\text { behavior }\end{array}$ & 66.67 & 28.57 & 57.14 & 0.00 & 0.00 & 75.00 & 75.00 \\
\hline View of society & 100.00 & 14.29 & 42.86 & 0.00 & 60.00 & 50.00 & 50.00 \\
\hline Conscious food intake & 66.67 & 57.14 & 42.86 & 0.00 & 20.00 & 37.50 & 50.00 \\
\hline Good conscience & 100.00 & 57.14 & 42.86 & 0.00 & 20.00 & 25.00 & 25.00 \\
\hline Positive affect & 33.33 & 100.00 & 42.86 & 66.67 & 60.00 & 25.00 & 50.00 \\
\hline Justification & 0.00 & 57.14 & 14.29 & 33.33 & 20.00 & 12.50 & 25.00 \\
\hline Importance of being satisfied & 0.00 & 28.57 & 0.00 & 0.00 & 40.00 & 0.00 & 0.00 \\
\hline Self-determined daily structure & 0.00 & 0.00 & 28.57 & 0.00 & 0.00 & 0.00 & 0.00 \\
\hline Development of own structures & 0.00 & 0.00 & 42.86 & 0.00 & 20.00 & 12.50 & 0.00 \\
\hline Homemade & 33.33 & 28.57 & 57.14 & 0.00 & 20.00 & 50.00 & 50.00 \\
\hline Rarely cooks & 33.33 & 0.00 & 14.29 & 100.00 & 20.00 & 25.00 & 25.00 \\
\hline Weight control & 0.00 & 28.57 & 28.57 & 66.67 & 40.00 & 75.00 & 75.00 \\
\hline $\begin{array}{l}\text { Development of own individual } \\
\text { health concept }\end{array}$ & 66.67 & 57.14 & 42.86 & 33.33 & 60.00 & 50.00 & 25.00 \\
\hline Adaptation to others & 33.33 & 14.29 & 14.29 & 0.00 & 60.00 & 12.50 & 0.00 \\
\hline Important part of family life & 0.00 & 42.86 & 14.29 & 0.00 & 80.00 & 12.50 & 0.00 \\
\hline Overstraining & 33.33 & 14.29 & 28.57 & 0.00 & 0.00 & 62.50 & 25.00 \\
\hline Negative affect & 0.00 & 0.00 & 28.57 & 0.00 & 0.00 & 75.00 & 25.00 \\
\hline Eating as a distraction & 0.00 & 14.29 & 14.29 & 0.00 & 0.00 & 37.50 & 0.00 \\
\hline Guilty conscience & 33.33 & 14.29 & 28.57 & 0.00 & 0.00 & 50.00 & 25.00 \\
\hline Balancing behavior & 0.00 & 14.29 & 0.00 & 0.00 & 40.00 & 12.50 & 100.00 \\
\hline Weighing process & 0.00 & 28.57 & 28.57 & 0.00 & 0.00 & 25.00 & 75.00 \\
\hline Exceptions (from control behavior) & 0.00 & 14.29 & 28.57 & 0.00 & 0.00 & 0.00 & 50.00 \\
\hline
\end{tabular}

the mind. The "body reference" $(n=18)$ therefore illustrates a strong need for body awareness, because the satisfaction of one's own demands and needs and thus the communication of a positive body awareness underlines the perceived positive effects of the idea of an ideal diet. "Subjectivization" $(n=10)$ takes the form of repeatedly relating one's own more radical lifestyle to that of others, along with the consequences and difficulties that go along with this. By gathering information, these people have adapted their behavior toward an idea of an ideal nutrition $(r=$ $0.905, p<0.001)$. The main reason for the behavioral change is the belief in natural physical needs (living in harmony with nature) $(r=0.713, p<0.001)$, which is an integral factor of the diet. The concept enables individuals of this type to reward themselves $(r=0.512, p<0.001)$, because, among other things, they repeatedly have to manage their own claims toward others ( $r=0.635, p<0.001$ ), which underlines the importance of subjectivization by making constant reference to them $(r=0.442$, $p<0.01)$.

\section{The Relaxed}

The Relaxed is represented by three men and four women, with an average age of 42.9 years. Five are of normal weight, one is overweight and one is obese. The Relaxed is characterized by a distinctly casual attitude to food. At the same time, emphasis is also placed on the person's own well-being. The quantitative content analysis identifies "body references" $(n=16)$ as a main topic, revealing that this type considers physical well-being to be important. Thus, The Relaxed makes reference to the body to underline the importance of eating a full and healthy diet. The second most frequent content is "community" $(n=15)$. For this type, "community" is important because of the benefits and positive associations of eating with other people and the way their eating behavior and meal requirements are affected in the presence of others. Their unique and decisive feature is their relaxed attitude toward food and their own diet $(r=0.565, p<$ $0.001)$ along with a desire to feel replete after eating $(r=0.416$, $p<0.05)$. 
TABLE 5 | Point biserial correlation [Significances (2 sided)] $(n=37)$ of the eating action types with important categories found in the qualitative content analysis.

\begin{tabular}{|c|c|c|c|c|c|c|c|}
\hline Variable & $\begin{array}{l}\text { Eating as a way } \\
\text { of life } \\
(N=3)\end{array}$ & $\begin{array}{l}\text { The Relaxed } \\
\qquad(N=7)\end{array}$ & $\begin{array}{l}\text { Eating as } \\
\text { self-determination } \\
\qquad(N=7)\end{array}$ & $\begin{array}{c}\text { Eating as a } \\
\text { necessary evil } \\
(N=3)\end{array}$ & $\begin{array}{l}\text { The Adaptive } \\
\qquad(N=5)\end{array}$ & $\begin{array}{c}\text { The } \\
\text { Overstrained } \\
(N=8)\end{array}$ & $\begin{array}{l}\text { The Controlled } \\
\qquad(N=4)\end{array}$ \\
\hline $\begin{array}{l}\text { Behavioral change by gathering of } \\
\text { information }\end{array}$ & $0.905^{\star \star}(0.000)$ & $-0.159(0.349)$ & $-0.159(0.349)$ & $-0.098(0.566)$ & $-0.130(0.444)$ & $-0.172(0.307)$ & $0.062(0.716)$ \\
\hline Dealing with own demands & $0.635^{\star \star}(0.000)$ & $-0.132(0.435)$ & $-0.132(0.435)$ & $-0.081(0.632)$ & $-0.108(0.524)$ & $0.046(0.786)$ & $-0.095(0.575)$ \\
\hline Rewarding & $0.512^{\star \star}(0.001)$ & $-0.077(0.652)$ & $-0.077(0.652)$ & $-0.114(0.501)$ & $-0.152(0.369)$ & $0.109(0.519)$ & $-0.134(0.430)$ \\
\hline Relating to others & $0.442^{\star \star}(0.006)$ & $-0.203(0.228)$ & $-0.090(0.596)$ & $-0.125(0.462)$ & $-0.166(0.326)$ & $-0.113(0.504)$ & $0.424^{\star \star}(0.009)$ \\
\hline Belief in natural physical needs & $0.713^{\star \star}(0.000)$ & $-0.105(0.538)$ & $-0.105(0.538)$ & $-0.111(0.512)$ & $-0.148(0.381)$ & $-0.197(0.243)$ & $0.159(0.346)$ \\
\hline $\begin{array}{l}\text { Reasoning of own consumption } \\
\text { behavior }\end{array}$ & $0.121(0.477)$ & $-0.162(0.338)$ & $0.121(0.476)$ & $-0.204(0.226)$ & $-0.272(0.104)$ & $0.285(0.087)$ & $0.046(0.786)$ \\
\hline View of society & $0.257(0.125)$ & $-0.232(0.168)$ & $0.126(0.459)$ & $-0.162(0.337)$ & $-0.067(0.692)$ & $0.145(0.391)$ & $-0.068(0.691)$ \\
\hline Conscious food intake & $0.053(0.755)$ & $0.029(0.864)$ & $0.029(0.864)$ & $-0.192(0.254)$ & $-0.125(0.460)$ & $0.148(0.382)$ & $-0.010(0.955)$ \\
\hline Good conscience & $0.264(0.114)$ & $0.105(0.536)$ & $0.213(0.205)$ & $-0.201(0.232)$ & $-0.144(0.395)$ & $-0.150(0.375)$ & $-0.099(0.558)$ \\
\hline Positive affect & $-0.141(0.407)$ & $0.565^{\star \star}(0.000)$ & $-0.160(0.346)$ & $0.008(0.962)$ & $-0.029(0.865)$ & $-0.216(0.200)$ & $-0.078(0.648)$ \\
\hline Justification & $0.121(0.477)$ & $-0.162(0.338)$ & $0.121(0.476)$ & $-0.204(0.226)$ & $-0.272(0.104)$ & $0.285(0.087)$ & $0.046(0.786)$ \\
\hline Importance of being satisfied & $-0.086(0.612)$ & $0.416^{\star}(0.010)$ & $-0.140(0.407)$ & $-0.086(0.612)$ & $0.098(0.565)$ & $-0.153(0.367)$ & $-0.101(0.551)$ \\
\hline Self-determined daily structure & $-0.071(0.676)$ & $-0.115(0.496)$ & $0.495^{\star \star}(0.002)$ & $-0.071(0.676)$ & $-0.094(0.578)$ & $-0.126(0.459)$ & $-0.083(0.624)$ \\
\hline Development of own structures & $-0.117(0.489)$ & $-0.191(0.258)$ & $0.415^{\star}(0.011)$ & $-0.117(0.489)$ & $0.075(0.659)$ & $-0.016(0.927)$ & $-0.138(0.417)$ \\
\hline Homemade & $0.205(0.224)$ & $0.032(0.851)$ & $0.032(0.851)$ & $-0.194(0.249)$ & $-0.099(0.560)$ & $-0.013(0.941)$ & $0.036(0.834)$ \\
\hline Rarely cooks & $-0.028(0.867)$ & $-0.260(0.120)$ & $-0.077(0.651)$ & $0.498^{\star \star}(0.002)$ & $-0.003(0.987)$ & $-0.021(0.901)$ & $0.044(0.797)$ \\
\hline Weight control & $-0.213(0.205)$ & $0.020(0.907)$ & $-0.265(0.113)$ & $0.079(0.642)$ & $-0.144(0.396)$ & $0.243(0.147)$ & $0.264(0.115)$ \\
\hline $\begin{array}{l}\text { Development of own individual } \\
\text { concept }\end{array}$ & $-0.003(0.986)$ & $0.180(0.287)$ & $-0.137(0.419)$ & $-0.117(0.492)$ & $0.056(0.740)$ & $0.045(0.792)$ & $-0.070(0.680)$ \\
\hline Adaptation to others & $0.138(0.416)$ & $-0.119(0.483)$ & $-0.025(0.882)$ & $-0.131(0.441)$ & $0.470^{\star *}(0.003)$ & $-0.142(0.402)$ & $-0.153(0.365)$ \\
\hline Important part of family life & $-0.148(0.382)$ & $0.053(0.756)$ & $-0.143(0.400)$ & $-0.148(0.382)$ & $0.587^{\star *}(0.000)$ & $-0.075(0.657)$ & $-0.173(0.305)$ \\
\hline Overstraining & $0.078(0.647)$ & $-0.182(0.280)$ & $-0.131(0.440)$ & $-0.144(0.396)$ & $-0.191(0.257)$ & $0.579^{\star \star}(0.000)$ & $-0.104(0.542)$ \\
\hline Negative affect & $-0.160(0.344)$ & $-0.260(0.120)$ & $0.015(0.930)$ & $-0.160(0.344)$ & $-0.213(0.205)$ & $0.634^{\star \star}(0.000)$ & $-0.014(0.934)$ \\
\hline Eating as a distraction & $-0.101(0.551)$ & $-0.078(0.648)$ & $-0.078(0.648)$ & $-0.101(0.551)$ & $-0.135(0.427)$ & $0.483^{\star \star}(0.002)$ & $-0.119(0.485)$ \\
\hline Guilty conscience & $-0.052(0.760)$ & $-0.107(0.529)$ & $0.094(0.579)$ & $-0.148(0.382)$ & $-0.197(0.242)$ & $0.376^{\star}(0.022)$ & $-0.089(0.600)$ \\
\hline Balancing behavior & $-0.138(0.416)$ & $0.072(0.672)$ & $-0.224(0.183)$ & $-0.138(0.416)$ & $0.043(0.802)$ & $-0.150(0.377)$ & $0.585^{\star \star}(0.000)$ \\
\hline Weighing process & $-0.147(0.386)$ & $0.014(0.936)$ & $-0.070(0.679)$ & $-0.147(0.386)$ & $-0.195(0.247)$ & $0.061(0.722)$ & $0.464^{\star \star}(0.004)$ \\
\hline Exceptions (from control behavior) & $-0.080(0.638)$ & $-0.061(0.719)$ & $0.007(0.965)$ & $-0.080(0.638)$ & $-0.106(0.531)$ & $-0.141(0.404)$ & $0.513^{\star \star}(0.001)$ \\
\hline
\end{tabular}

${ }^{*}$ The correlation is significant at the level of 0.01 (2-sided). ${ }^{*}$ The correlation is significant at the level of 0.05 (2-sided). 
TABLE 6 | Joint presentation of qualitative and quantitative data.

\begin{tabular}{|c|c|}
\hline $\begin{array}{l}\text { Eating } \\
\text { action type }\end{array}$ & $\begin{array}{l}\text { Distinctive features based on quantitative analysis of } \\
\text { qualitative data }\end{array}$ \\
\hline $\begin{array}{l}\text { Eating as a } \\
\text { way of life }\end{array}$ & $\begin{array}{l}\text { Main food-related contents: Body } \\
\text { reference; subjectivization } \\
\text { Significant unique features: Behavioral change by } \\
\text { gathering information; Dealing with own demands; rewarding; } \\
\text { relating to others; belief in natural physical needs }\end{array}$ \\
\hline The relaxed & $\begin{array}{l}\text { Main food-related contents: Body reference; community } \\
\text { Significant unique features: Positive affect toward eating } \\
\text { day(s); importance of being satisfied }\end{array}$ \\
\hline $\begin{array}{l}\text { Eating as } \\
\text { self- } \\
\text { determination }\end{array}$ & $\begin{array}{l}\text { Main food-related contents: Intended behavior; community } \\
\text { Significant unique features: Self-determined daily } \\
\text { structure; development of own individual structures }\end{array}$ \\
\hline $\begin{array}{l}\text { Eating as a } \\
\text { necessary } \\
\text { evil }\end{array}$ & $\begin{array}{l}\text { Main food-related content: Habits } \\
\text { Significant unique features: Rarely cooks }\end{array}$ \\
\hline The adaptive & $\begin{array}{l}\text { Main food-related contents: Community; habits } \\
\text { Significant unique features: Adaptation to others; eating } \\
\text { as an important part of family life }\end{array}$ \\
\hline $\begin{array}{l}\text { The } \\
\text { overstrained }\end{array}$ & $\begin{array}{l}\text { Main food-related contents: Body reference; } \\
\text { intended behavior } \\
\text { Significant unique features: Overstraining; negative affect } \\
\text { toward eating day(s); eating as distraction; guilty conscience }\end{array}$ \\
\hline $\begin{array}{l}\text { The } \\
\text { controlled }\end{array}$ & $\begin{array}{l}\text { Main food-related contents: Body reference; } \\
\text { control behavior } \\
\text { Significant unique features: Relating to others; balancing } \\
\text { behavior; weighing process; exceptions (from } \\
\text { control behavior) }\end{array}$ \\
\hline
\end{tabular}

\section{Eating as Self-Determination}

Two men and five women represent this type. With an average age of 38.7 years, it is the youngest group of eating action types. Only one individual of this type is overweight, while the others are of normal weight.

This type is strongly focused on itself in terms of independence from others. The feeling of being dependent is considered stressful by this type. The "intended behavior" $(n=$ 21 ) is one of the issues that Eating as self-determination often refers to, which emphasizes the endeavor to use fresh food, to prepare meals according to one's needs and to consume in a moderate, regular and healthy way. The behavior therefore refers to the use, preparation and consumption of food. The intended behavior again underlines the other aspect, the need to be independent of others. Eating as self-determination thus refers to "community" $(n=18)$ to underline his or her own distinctiveness from other people. The personal attitude toward food is then clear: the individuals in this type set themselves apart from and compare themselves with others, and the behavior of others is reflected on and evaluated. Since a self-determined daily structure is of central importance $(r=0.495$. $p<0.01)$, this category is not mentioned by any other type: The examination of society serves to delimit and emphasize the self and its needs, as does the development of one's own structures and the abandoning of behaviors learned from parents $(r=0.415$, $p<0.05)$.

\section{Eating as a Necessary Evil}

Two women and one man are the representatives of this type, which is the oldest of all the eating action types with an average age of 81.7 years. Two of the individuals are overweight and one is of normal weight.

For this type, neither eating itself nor any other food-related behavior plays any relevant role; eating is considered to have no meaning or value. The main finding of the content analysis was found during the interviews to be "habits" $(n=5)$. This underlines the routines that characterize food-related behavior, indicating the insignificance of food and eating. The same established and familiar behaviors shape this type's food-related behavior, indicating an unwillingness to address the topic more intensively. The fact that this type rarely cooks is also fitting $(r=$ $0.498, p<0.01)$.

\section{The Adaptive}

Four men and one woman represent this eating action type. The average age of this type is 55.4 years; three are of normal weight, one person is overweight and one is obese.

The Adaptive type is mainly characterized by a tendency to adapt to others. This is underlined by the results of the quantitative content analysis, which shows the importance of the community for providing a food-related behavior; "community" ( $n=9$ ) is therefore the main topic of this type. The Adaptive makes reference to "community," indicating that social interaction plays a significant role. Food and eating is understood as an essential aspect of family and social life $(r=0.587, p<$ 0.001 ). This fact is always in the foreground when it comes to eating and leads to a situational adaptation of the type's own food-related behavior to that of others $(r=0.470, p<0.01)$. A noteworthy aspect is the frequent use of us or we, which underpins the adaptation to others. A further important issue is "habits" $(n=7)$, which indicate a partly shared standardized behavior. The Adaptive refers to this content by emphasizing family meal rituals.

\section{The Overstrained}

Six men and two women, with an average age of 53.8 years, represent The Overstrained. Five people of this type have normal weight, two are overweight and one is obese.

The Overstrained is characterized by a failure to implement a consistent positive attitude toward food. Thus, this type makes repeated "body references" $(n=20)$ due to the negative impact of their inconsistent and stressful behavior on the body. However, these references differ greatly due to the individual's failure to meet existing demands (e.g., having no physical limitations despite having a high weight, a lack of self-respect for the body, a desire to stay fit, an unwanted feeling of fullness). The "intended behavior" ( $n=17)$ stands for all the attempts that are made in the mind to change the situation. Significantly, these attempts tend to remain in the mind, and no actual changes occur. People of this type are aware of what they should (and should not) be doing, but for various reasons, they do not do it, which then leads to overstraining ( $r=0.579, p<0.001)$. In general, this leads to a negative affect toward eating day(s) $(r=0.634, p<0.001)$. This in turn leads to using food as a distraction $(r=0.483, p<0.01)$, 
followed by a guilty conscience ( $r=0.367, p<0.05)$, which also results from an inability to change the situation.

\section{The Controlled}

This type is represented by two men and two women. The average age is 45.8 years, and three individuals are of normal weight, while one is overweight.

The Controlled type is characterized by a highly controlled behavior. The emphasis is on the body, which is required to meet the person's own high standards. The results of the quantitative content analysis revealed "body reference" $(n=20)$ as the main issue for this type. For The Controlled, the all-influencing importance of low body weight is emphasized, leading to generally controlling behavior. Thus, "control behavior" $(n=16)$ stands here for the constant need to meet one's own physical demands. To achieve this, the abandonment of certain foods or meals is an acceptable price $(r=0.585, p<0.001)$. Body image is of particular importance, weakened or strengthened by comparisons with others $(r=0.424, p<0.01)$. This constant preoccupation with one's own body leads to balancing previous and present consumption and weighing up present consumption with what has already been consumed and what may still be consumed $(r=0.464, p<0.01)$. Although this behavior is very restrictive, it is not considered to be an eating disorder, because people of this type repeatedly allow themselves exceptions to the controlled behavior $(r=0.513, p<0.001)$.

\section{DISCUSSION AND CONCLUSIONS}

The purpose of this paper was to analyze more deeply the previously built eating action types by bringing their decisive features more into focus. To do this, we applied quantitative analysis of qualitative data.

Through our analysis, we were able to identify the different challenges, their effects and ways of dealing with them that occur through eating together and eating alone in everyday life, through which personality and, consequently, socialization are lived. The quantification of our data highlights the essential characteristics of the individual types, thus showing the different focal points in dealing with the integration of food into everyday life. These in turn can be clustered and so there are seven ways in how people integrate food into their everyday lives, their reasons and the challenges they face in doing so. Therefore, Eating as a way of life defends the own behavior, which is strongly influenced by the belief in natural physical needs, and by constantly establishing and presenting the reference to others in the context of the own demands. The subjective view plays an essential role, encompassing a unified system that is defended and lived by. For The Relaxed, positive associations with food play a role above all: the strong need to be sufficiently and well-nourished is pursued with certain lightness. For Eating as self-determination, the selfdetermined daily structure is in the foreground; it focuses on the development of individual structures and rejects the familiar. That eating hardly plays a role for Eating as a necessary Evil is confirmed by the rare cooking. The adaptation to others, which stands in strong contrast to Eating as self-determination, i.e., not forming own structures, but rather going along with it and focusing on the community aspect, reflects the behavior of The Adaptive. The challenges of The Overstrained are only met with overstraining, which is reflected in the bad feeling about food-related behavior, the guilty conscience, but also in distraction behavior. The Controlled are constantly negotiating and weighing up what is allowed and what is not, in order to feel good in their own bodies. In doing so, they constantly relate to others, compare themselves and devalue the behavior of others.

\section{Methodological Considerations}

Quantitative analysis of the qualitative data enables an enhanced distinction between individual eating action types and pinpoints their particular distinguishing features, giving us a detailed insight into the characteristics of the types. This article shows that quantitative analysis techniques can also be used with small case numbers and can contribute to a general understanding of the thematic content. This indicates the benefit of the crossover analysis as the cross tab stressed special characteristics and the results of the point biserial correlation underline significant unique features of these special characteristics. The result is an increased and more focused differentiation between the eating action types that give a clear insight into how people integrate eating into everyday lives while engaging with themselves and the environment.

The limitations of the methods used in this project are due to the small number of cases. Thus, it is not possible to describe this as a representative study. The results of the study should be tested to ascertain their significance for a representative cross section of the population.

It would also be interesting to determine to what extent our approach and the corresponding results can be transferred to other areas of consumption. This would serve to test and verify our design. Additionally, after repeated testing, our approach could serve as the basis for developing an instrument that can identify different types in differing areas of consumption.

Furthermore, the development of a dictionary requires a lot of manual effort, since MAXQDA cannot evaluate content logic. Accordingly, each assignment requires human verification, which is very time-consuming and error-prone. Evaluation by a scientist is a subjective process. On grounds of capacity, only one scientist, the first author, reviewed the text passages assigned to the respective categories. Thus, it cannot be excluded that this also influenced the results of this study.

Since this study was conducted in one particular region of Germany (Bavaria), it is necessary to investigate whether the eating action types identified can be verified for the whole area of Germany.

Since food-related behavior differ in different nations and cultures, other questions concerns what changes might occur if the approach were to be transferred to other countries or cultural areas. 


\section{Discussion of Factual Findings}

As a result of changes in society and the multiple options that are now available, eating culture has become more heterogeneous in Germany $(27,69)$. Our study confirms these findings by highlighting the peculiarity of each eating action type to determine the unique features of each individual eating action type. Nitzko and Spiller (70) revealed that pleasure orientation, slimness and well-being, and health and diversity are essential factors that influence food-related behavior. All of these aspects can be found in our types: pleasure orientation is an important aspect for The Relaxed, slimness is of high relevance for The Controlled, well-being is significant for every eating action type, and health is especially important for Eating as a way of life, whereas diversity is represented by the different types.

A detailed comparison of the findings of this study with previous segmentation studies in Germany is restricted by differences in the studies' foci. Our study focuses on the eating action question of how people integrate eating into everyday lives, while other studies mainly focus on the food itself, e.g., the question of what is eaten $(21-23,25)$ or have special thematic foci (28-31). Thus, we highlight findings of this study that are comparable with each other.

With regard to the Nestlé Nutrition Types (25) we find that Eating as a way of life is comparable with The health idealists ["Gesundheitsidealisten," (25)] in the sense that they predominantly comprise ecologically conscious women who wish to live in harmony with nature, adapting their current lifestyle by obtaining new information (25). We did not find a comparison group for The Relaxed. The Nestlé nutrition study also includes a Modern Multi-Optional type ["Die modernen Multi-Optionalen," (25)] which can be compared with Eating as self-determination. Both groups have in common that they are relatively young, with ages of 26-55 and live in a dichotomy between their own high demands and a tight time budget. The dispassionate pragmatists ["Die leidenschaftslosen Pragmatiker," (25)] can be compared with Eating as a necessary Evil. Similarities can be found in the age structure, the level of sophistication, and the satisfaction with the status quo. Food intake in this group is simply seen as a means to an end, but there are fixed dietary rituals and emphasis is placed on regular meals. Characteristics such as those that we found in the Adaptive type can also be seen in The Nest Warmers ["Nestwärmer," (25)]. This group covers all age groups. Here, family and tradition are very important, harmony is strived for and joint meals with family and friends are very important.

Interestingly, The Overstrained is not found as an independent group in any other nutritional typology (21-23, 25, 28-31). Only some types mentioning inner conflicts and ambivalences are identified in previous studies. However, these types do not have a general character, but are concerned with partial aspects (31). However, The Overstrained is actually the largest group in our study, with a total of eight persons. Hayn (69) and Jastran et al. (71) refer to the fact that once established, everyday actions are not constantly reflected upon because they reduce complexity, offer strong relief potential and provide stability and security "because life runs more smoothly when things become predictable and expected from day to day and week to week" (71). However, these everyday actions have to be actively constructed, stabilized, maintained and changed by each individual (69). With regard to The Overstrained, the results of our study suggest that many people fail to implement actively everyday food-related behavior due to internal or external changes that are actively affecting them and that lead to non-well-being due to implicit motives that are not congruent with their external motives $(51,72)$. However, this motive incongruence cannot be revealed by examining foodrelated behavior only with a standardized questionnaire. Rather, standardized questionnaires describe how people actually behave; but it is hard to determine by means of closed questions whether behind the behavior described lies a (great) overstraining. Only through the combination of qualitative and quantitative research methods, it was possible, on the one hand, to identify the group of The Overstrained qualitatively and, on the other hand, to confirm and emphasize it through statistical analysis. Otherwise, overstraining in the context of food-related behavior is only taken into account by studies focusing on people with specific eating disorders (anorexia, bulimia, etc.) (73). However, as our study suggests, there are people with a healthy mental attitude to food who nevertheless feel overstrained. Moreover, the absolute number of overweight and obese people is highest in The Overstrained group. Taking the definition of the WHO, 37.5\% of people of The Overstrained weigh too much (43). Bruhn (28) shows that social changes and changes in the environment are the main reasons for the rapid increase in overweight and obesity (28). Only Eating as a necessary Evil and The Adaptive show higher rates of overweight and obesity. However, Eating as a necessary Evil is the oldest eating action type, and weight gain in old age is due to changes in a person's metabolism and energy requirements (74).

The Controlled can best be compared with the Fitness-oriented and ambitious type ["Die fitnessorientierten Ambitionierten," (31)] of the study by Stieß and Hayn (31). This type is characterized, among other things, by an effort to maintain high levels of performance and fitness and to keep the body attractive through controlled eating. Individual success is measured primarily in terms of the perception of others, which is why some people attach so much importance to their own appearance (31).

Another interesting aspect is that of the sense of community created by eating together. Joint meals are of great importance to many people, even though the community-building role of eating is actually becoming less important (27). Our study confirms both findings, as eating together is indeed of great importance to many of our participants, while some struggle with the food-related behavior of other people, placing the focus on their own foodrelated behavior (Eating as a way of life, The Relaxed, Eating as self-determination and The Controlled). For Eating as a necessary Evil, eating as such does not play a relevant role, therefore nor does eating together.

With this study, we have shown that quantitative analysis of the qualitative data was able to identify an improved distinction between the individual eating action types and show their particular distinguishing features, giving us a detailed insight into the characteristics of each type. As a major result, we did 
not find a comparison group for The Relaxed, nor for The Overstrained in previous literature. Interestingly, these two are the groups that seem to be the most opposed to each other that have so far received little attention in terms of their extent as a single group. The result of The Overstrained as a distinct group deserves special emphasis. This group does not suffer from a mental eating disorder; rather they would like to know a relaxed way of integrating food into their everyday life. Yet they fail and often suffer from obesity. The desire to find a sensible way to integrate eating into everyday life should be taken into account for people of this type by nutritional counseling, policies and advertisers.

In this study, we were able to show the main content of each type when it comes to eating. It was shown that an idea of an ideal nutrition leading to physically and ethically well-being, having a relaxed attitude toward eating, self-determination, the body as an instrument of control, adaptation and overstraining play relevant roles when it comes to how people integrate eating into their everyday life and thus experience personality development and related socialization. In the group comparison, it became clear that the reference to the body occurs repeatedly, although the reference can have different origins, e.g., the need to feel good physically, or the need to maintain control over the body or to live in harmony with nature. In addition, the reference to the "community" is increasingly established, but here too from different perspectives, either because the presence of others is stressful or relaxing. The need for subjectivization and for control is unique: these two contents can be found in only one type each and thus distinguish them in particular. The crossover analysis, in turn, confirms the results of the qualitative built types and underpins the respective eating action types in their characteristics, with which they distinguish themselves from each other. Thus, this study is the first food-related consumer segmentation study for Germany that uses a mixedmethods approach, which expands the methodological toolkit in this field.

In this study, we have shown what methods are applied individually when it comes to how people integrate eating into their everyday lives and thus experience personality development and related socialization. Special intervention is needed for The Overstrained. Therefore, the reasons for the overstrain must be looked at closely, which can also be caused by external factors, so personal contact is needed that takes the social system into account [keyword: systemic approach (75)]. The Controlled could also profit from systematic approaches, because of their constantly reproduced reference to their environment and its evaluation. Moreover, for The Controlled, education about physical needs would probably be useful, because the constant compensatory behavior is exhausting for the body. It is much more important to have regular mealtimes and a balanced diet. One idea would be to cooperate with the people of The Relaxed and benefit from their experiences, and from the ways to establish a relaxed approach to eating, for example by having participatory processes, where mutual reporting and learning from each other is possible. This seems to make sense insofar as classical nutrition communication often fails due to its abstraction and the lack of a realistic assessment to the target groups (76). A participative procedure would be a procedure at eye level, where solutions are worked out together (77). The results of this study can also help to support the need for self-determined daily structure by creating individual plans for Eating as a self-determination with the help of professional coaching, because the implementation of the own desired structure is the special challenge of this group. However, inability leads to discomfort. Thus, people of Eating as self-determination need to get the feeling of being able to organize eating situations independently, despite the given structure of everyday life.

Due to the adaptability of The Adaptive and their wellbeing with it, it seems debatable whether the introduction of an intervention for this type is necessary. On the one hand, it could be thought that it makes sense to develop own foodrelated behavior structures in order to minimize the dependency factor on others. On the other hand, this type expresses a good feeling about the nature of their own food-related behavior (40). Accordingly, it could make sense to bring certain family products or community-promoting products onto the market; or to promote the formation of their own structures by means of a systemic approach or a professional coaching.

Special product marketing could be helpful for Eating as a necessary Evil. For this type of people, products could be offered on the market that are easy to prepare and at the same time have a high nutrient density or an adapted nutrient profile. Such products should be specially positioned in the supermarket and accompanied by targeted communication measures for this special group (78). Also for Eating as a way of life, appropriate products such as vegan, vegetarian, or products that are strongly unprocessed and in harmony with nature should be increasingly brought to the market.

With this study, we have identified and described significant features of the eating action types often overlooked and taken a first step toward generalizing the results of the qualitatively built eating action types. It can be understood as a preliminary step toward deriving a general typology that does not have a thematic focus, refers to the population as a whole and focuses on the individual. However, the results should be further explored in qualitative and quantitative studies in future in an international context to show whether there are e.g., cultural influences or differences between countries. The results of this study are a valuable tool for nutrition consultancies, food companies, policy makers and advisors to consider the different ways people integrate food into their daily lives in their own specific actions. This may improve the commercial performance of commercial companies, but also increase the effectiveness of policy initiatives and advisory and educational activities in the field of food and eating.

\section{DATA AVAILABILITY STATEMENT}

The raw data supporting the conclusions of this article will be made available by the authors, without undue reservation. 


\section{ETHICS STATEMENT}

Ethical review and approval was not required for the study on human participants in accordance with the local legislation and institutional requirements. The patients/participants provided their written informed consent to participate in this study.

\section{AUTHOR CONTRIBUTIONS}

LL conceived, designed, performed the experiments, analyzed the data, and wrote the draft of the paper. AE-K and KM contributed

\section{REFERENCES}

1. Rozin P. The integration of biological, social, cultural and psychological influences on food choice. In: Shepherd R, Raats M, editors. Frontiers in Nutritional Science: No. 3. The Psychology of Food Choice. Wallinford: CABI (2006).

2. Ott C. Identität geht durch den Magen: Mythen der Esskultur. Frankfurt am Main: Fischer Verlag GmbH (2017).

3. Schnurr EM. Die Besser-Esser. (2006). Available online at: https://www.zeit.de/ zeit-wissen/2006/05/Titel_Ernaehrung.xml (accessed September 30, 2019).

4. Holm L, Gronow J, (Eds.). Everyday Eating in Denmark, Finland Norway and Sweden: A Comparative Study of Meal Patterns 1997-2012. New York, NY: Bloomsbury Academic (2019).

5. Murcott A. Understanding life-style and food use: contributions from the social sciences. Br Med Bull. (2000) 56:121-32. doi: 10.1258/0007142001902833

6. Warde A. The Practice of Eating. CambridgeMA: Polity Press (2016).

7. Frewer L, van Trijp H. Understanding Consumers of Food Products. Woodhead Publishing in Food Science, Technology and Nutrition. Boca Raton, MA: CRC (2007).

8. Grunert KG. Current issues in the understanding of consumer food choice. Tren Food Technol. (2002) 13:275-85. doi: 10.1016/S0924-2244(02)00137-1

9. Mela DJ. Food choice and intake: The human factor. Proc Nutr Soc. (1999) 58:513-21. doi: 10.1017/S0029665199000683

10. Plessz M, Wahlen S. All practices are shared, but some more than others: Sharedness of social practices and time-use in food consumption. J Consumer Cult. (2020) 2:146954052090714. doi: 10.1177/1469540520907146

11. Klotter C. Identitätsbildung über Essen. Wiesbaden: Springer Fachmedien (2016).

12. Köster EP. Diversity in the determinants of food choice: A psychological perspective. Food Q Preference. (2009) 20:70-82. doi: 10.1016/j.foodqual.2007.11.002

13. Pudel V, Westenhöfer J. Ernährungspsychologie: Eine Einführung (3rd, unchanged ed.). Göttingen: Hogrefe (2003).

14. Kluge S. Empirically grounded construction of types and typologies in qualitative social research. Forum Q Sozialforschung. (2000) 1:14. doi: 10.17169/fqs-1.1.1124

15. Diaz-Bone R, Weischer C. Methoden-Lexikon für die Sozialwissenschaften. Wiesbaden: Springer VS (2015).

16. Kuckartz U. Qualitative Text Analysis: A Guide to Methods, Practice \& Using Software. United States: SAGE (2014).

17. Silver C. Conference report: CAQD conference 2013 [32 paragraphs]. Forum Q Sozial. (2013) 14:24. doi: 10.17169/fqs-14.2.2001

18. Wienold H. Typus. In: Fuchs-Heinritz W, editors. Lexikon zur Soziologie. Wiesbaden: VS Verlag für Sozialwissenschaften (2013).

19. Brusten M. Typifikation. In: Fuchs-Heinritz W, editor. Lexikon zur Soziologie. Wiesbaden: VS Verlag für Sozialwissenschaften (2013).

20. Kuckartz U. Qualitative Inhaltsanalyse. Methoden, Praxis, Computerunterstützung. Grundlagentexte Methoden. Weinheim: Beltz Juventa (2016). to the writing and evaluation process. All authors contributed to the article and approved the submitted version.

\section{FUNDING}

The preparation of this paper was supported by the enable Cluster and is cataloged by the enable Steering Committee as enable 05 (http://enable-cluster.de). This work was funded by the German Ministry for Education and Research (BMBF) (Grant number: FKZ01EA1409D). The authors greatly acknowledge this financial support but remain solely responsible for the content of this manuscript.

21. Czinkota B. Die 7 Ernährungstypen - Worauf wir beim Essen achten. (2017). Available online at: https://www.nielsen.com/de/de/insights/article/2017/wp12-esser/ (accessed August 4, 2020).

22. G+J Media Sales. Neue Food-Studie ermittelt Ernährungstypen: "Naturisten" und "Tafelfreudige" zwischen Vernunft und Versuchung [Press release]. Hamburg. (2012)

23. GfK. Consumers' Choice '15: Die Auflösung der Ernährungsriten - Folgen für das Ess- und Kochverhalten. Available online at: https://www.bve-online.de/ presse/infothek/publikationen-jahresbericht/consumers-choice-2015 (2015).

24. Janke K. So is(s)t Deutschland: Nestlé Studie 2009. Frankfurt am Main: Nestlé Deutschland AG (2009).

25. Nestlé Deutschland AG. Ernährungstypen: Welchen Stellenwert hat Ernährung in Ihrem Leben? (2021). Available online at: https://www. nestle.de/ernaehrung/ernaehrungstypen (accessed April 21, 2021).

26. Oltersdorf U. Verbrauchertypologien. (2019). Available online at: http:// ernaehrungsdenkwerkstatt.de/ernaehrungsforschungsraum/menschen/ individuum-mensch/typen-von-menschen.html (accessed October 17, 2019).

27. Nestlé Deutschland AG. So Geteilt is $(s) t$ Deutschland [Press release]. Available online at: https://www.nestle.de/medien/medieninformationen/ nestl\%C3\%A9-studie-2019 (2019).

28. Bruhn M. Lebensstil-Entscheidungstypologie des Ernährungsverhaltens Implikationen für die Verhaltensprävention. In: Lecture on the Occasion of the 48th Annual Conference of GEWISOLA. Bonn (2008).

29. Brunsø K, Grunert KG, Bredahl L. An Analysis of National and Cross-National Consumer Segements Using the Food-Related Lifestyle Instrument in Denmark, France, Germany and Great Britain. (1996). Available online at: https://pure. au.dk/portal/files/32299546/wp35.pdf (accessed May 29, 2019).

30. Kluß N. Essen und Essgenuss: Qualitative Untersuchung zur individuellen Bedeutung von Essgenuss, Genussfähigkeit und Genussorientierung im Essalltag. Chancen eines genuss- und sinnesorientierten Ansatzes für schulische Bildungsprozesse. (2018). Available online at: https://opus.ph-heidelberg.de/ frontdoor/deliver/index/docId/321/file/Dissertation+Essen+und+Essgenuss_ Nicola+Klu\%c3\%9f.pdf (accessed May 29, 2021).

31. Stieß I, Hayn D. Ernährungsstile im Alltag: Ergebnisse einer repräsentativen Untersuchung. Diskussionspapier (2005).

32. Abels H, König A. Hurrelmann: produktive verarbeitung der realität. In: H. Abels and A. König, editors. Sozialisation. Wiesbaden: Springer Fachmedien (2016).

33. Hurrelmann K, Bauer U. Einführung in die Sozialisationstheorie: Das Modell der produktiven Realitätsverarbeitung (11th, fully revised edition). Weinheim: Beltz (2015).

34. Brinkmann S, Kvale S. InterViews: Learning the Craft of Qualitative Research Interviewing (Third edition). Los Angeles, CA: Sage Publications (2015).

35. Flick U. Qualitative Sozialforschung: Eine Einführung (Original edition, 8th edition). Rororo Rowohlts Enzyklopädie: Vol. 55694. Reinbek bei Hamburg: rowohlts enzyklopädie im Rowohlt Taschenbuch Verlag (2017).

36. Creswell JW. A Concise Introduction to Mixed Methods Research. Thousand Oaks, CA: SAGE (2015).

37. Schumann S. Quantitative und Qualitative empirische Forschung. Wiesbaden: Springer VS (2018). 
38. Spiekermann U. Von der agricultur zur ernährungskultur. Eine begriffsgeschichtliche Analyse. In: Bundesamt für Naturschutz BfN, editors. Ernährungskultur: Land(wirt)schaft, Ernährung und Gesellschaft.: 26. Wissenschaftliche Jahrestagung der AGEV. BfN-Skripten (2004).

39. Johnson RB, Onwuegbuzie AJ, Turner LA. Toward a definition of mixed methods research. J Mixed Methods Res. (2007) 1:112-33. doi: $10.1177 / 1558689806298224$

40. Lampmann L, Emberger-Klein A, Grau M, Menrad K. Ways of integrating eating into everyday lives - A Qualitative Study in Germany (n.d.).

41. Witzel A. The problem-centered interview. Forum Q Soc Res. (2000) 1:1. doi: $10.17169 /$ fqs-1.1.1132

42. Saunders B, Sim J, Kingstone T, Baker S, Waterfield J, Bartlam B, et al. Saturation in qualitative research: Exploring its conceptualization and operationalization. Q Quant. (2018) 52:1893-907. doi: 10.1007/s11135-017-0574-8

43. WHO. Body Mass Index - BMI. (2019). Available online at: http://www.euro. who.int/en/health-topics/disease-prevention/nutrition/a-healthy-lifestyle/ body-mass-index-bmi (accessed August 22, 2021).

44. Kluge S, Kelle U. Vom Einzelfall zum Typus: Fallvergleich und Fallkontrastierung in der qualitativen Sozialforschung. Wiesbaden: VS Verlag für Sozialwissenschaften (2010).

45. Kuckartz U. Zwischen singularität und allgemeingültigkeit: typenbildung als qualitative strategie der verallgemeinerung. In: Rehberg KS, Deutsche Gesellschaft für Soziologie, editors. Soziale Ungleichheit, kulturelle Unterschiede: Verhandlungen des 32. Kongresses der Deutschen Gesellschaft für Soziologie in München. Frankfurt am Main (2006).

46. Dijker AJM. Moderate eating with pleasure and without effort: toward understanding the underlying psychological mechanisms. Health Psychol Open. (2019) 6:1-17. doi: 10.1177/2055102919889883

47. Deci EL, Ryan RM. Intrinsic Motivation and Self-Determination in Human Behavior. New York, NY: Plenum (1985).

48. Deci E, Ryan RM. The "What" and "Why" of goal pursuits: human needs and the self-determination of behaviour. Psychol Inquiry. (2000) 11: 227-68.

49. Cappelletti C, Corse L, Kinney A, Lapalme S, Sandygren N, Scribner D, et al. Nutrition and social eating habits among seniors living independently. Pub Health Proj. (2010) 34.

50. Chernyakova N. Value resource of social adaptation and professionalism. In: Scientific Research in the XXI Century: Proceedings of the I International Scientific Conference on Eurasian Scientific Cooperation. (2014). p. 114-118.

51. Job V, Oerting D, Brandstätter V, Allemand M. Discrepancies between implicit and explicit motivation and unhealthy eating behavior. $J$ Personal. (2010) 78:1209-38. doi: 10.1111/j.1467-6494.2010.006 48.x

52. Klein G. Soziologie des Körpers. In Kneer G, Schroer M, editors. Handbuch spezielle Soziologien, 1st edn., Wiesbaden: Verlag für Sozialwissenschaften. (2010). p. 457-73.

53. Lane DC. Understanding body modification: A process-based framework. Sociol Compass. (2017) 11:1-15. doi: 10.1111/soc4.12495

54. Berelson B. Content Analysis in Communication Research. Glencoe, Ill.: Free Press (1952).

55. Rourke L, Anderson T. Validity in quantitative content analysis. Educ Technol Res Dev. (2004) 52:4769. doi: 10.1007/BF02504769

56. Prahl HW, Setzwein M. Soziologie der Ernährung. Opladen: Leske und Budrich (1999). doi: 10.1007/978-3-322-99874-3

57. Onwuegbuzie AJ, Combs JP. Emergent data analysis techniques in mixed methods research: a synthesis. In: Tashakkori A, Teddlie C, editors. SAGE Handbook of Mixed Methods in Social \& Behavioral Research. United States: SAGE Publications, Inc. (2010).

58. Vogl S. Quantifizierung. KZfSS Kölner Zeitschrift Für Soziologie Und Sozialpsychologie. (2017) 69:287-312. doi: 10.1007/s11577-017-0461-2

59. Greene JC, Caracelli VJ, Graham WF. Toward a conceptual framework for mixed-method evaluation designs. Educ Eval Policy Analy. (1989) 11:255-74. doi: 10.3102/01623737011003255

60. Li S, Marquart JM, Zercher C. Conceptual issues and analytic strategies in mixed-method studies of preschool inclusion. J Early Intervent. (2000) 23:116-32. doi: 10.1177/105381510002300206

61. Caracelli VJ, Greene JC. Data analysis strategies for mixed-method evaluation designs. Educ Evaluat Policy Analy. (1993) 15:195-207. doi: $10.3102 / 01623737015002195$
62. Tashakkori A, Teddlie C, (Eds.). SAGE Handbook of Mixed Methods in Social \& Behavioral Research (2nd Edition). United States: SAGE Publications, Inc. (2010). doi: 10.4135/9781506335193

63. Sandelowski M, Voils CI, Knafl G. On quantitizing. J Mixed Methods Res. (2009) 3:208-22. doi: 10.1177/1558689809334210

64. Flick U. Triangulation: Eine Einführung. Wiesbaden: VS Verlag für Sozialwissenschaften (2004).

65. Seipel C, Rieker P. Integrative Sozialforschung: Konzepte und Methoden der qualitativen und quantitativen empirischen Forschung. Weinheim: Juventa (2003).

66. MAXQDA [Computer software] (2020): Verbi GmbH.

67. SPSS Statistics 25 [Computer software] (2020): IBM.

68. Cohen J, Cohen P, West SG, Aiken LS. Applied multiple regression/correlation analysis for the behavioral sciences (Third edition). New York, NY: Routledge, Taylor \& Francis Group (2003).

69. Hayn D. Ernährungshandeln im Alltag: Der Ernährungsalltag als komplexer, sich stetig wandelnder Handlungszusammenhang. Ernährungs Umschau. (2008) 55:346-51. https://www.ernaehrungs-umschau.de/fileadmin/ Ernaehrungs-Umschau/pdfs/pdf_2008/06_08/EU06_346_351.qxd.pdf (accessed August 22, 2021).

70. Nitzko S, Spiller A. Zielgruppenansätze in der lebensmittelvermarktung. In: Halfmann $\mathrm{M}$, editors. Zielgruppen im Konsumentenmarketing: Segmentierungsansätze, Trends, Umsetzung. Wiesbaden: Springer Gabler (2014).

71. Jastran MM, Bisogni CA, Sobal J, Blake C, Devine CM. Eating routines. Embedded, value based, modifiable, and reflective. Appetite. (2009) 52:127-36. doi: 10.1016/j.appet.2008.09.003

72. Lampmann L, Emberger-Klein A, Menrad K. Is there a relationship between implicit motives and eating action types - an exploratory study in Germany. $J$ Consumer Cult. (2021) 78:1-19. doi: 10.1177/14695405211013954

73. Kathrein A. Überwindung der Essstörung als Weg ins Gleichgewicht: Ein Modell $z u$ persönlichen Entwicklungsprozessen aus Anorexie und Bulimie. Wiesbaden: Springer Fachmedien (2019). doi: 10.1007/978-3-658-25971-6

74. Herzner S. Gewicht: Jedes Jahr ein Kilo mehr? (2016). Available online at: https://www.apotheken-umschau.de/Abnehmen/Gewicht-Jedes-Jahr-einKilo-mehr-108247.html (accessed July 23, 2020).

75. Schlippe A, Schweitzer J. Lehrbuch der systemischen Therapie und Beratung I: Das Grundlagenwissen (3., unveränderte Auflage). Göttingen: Vandenhoeck \& Ruprecht (2016). doi: 10.13109/9783666401855

76. Barlösius E, Rehaag R, (Eds.). Skandal oder Kontinuität: Anfoderungen an eine öffentliche Ernährungskommunikation. (Discussion Papers / Wissenschaftszentrum Berlin für Sozialforschung, Forschungsschwerpunkt Bildung, Arbeit und Lebenschancen, Forschungsgruppe Public Health, 2006-306). Berlin: Wissenschaftszentrum Berlin für Sozialforschung gGmbH (2006).

77. Unger H. Partizipative Forschung: Einführung in die Forschungspraxis. Lehrbuch. Wiesbaden: Springer VS (2014)

78. Lampmann L, Hannink A, Kiesswetter E, Emberger-Klein A, Volkert D, Menrad K. Protein for community-dwelling older people: aspects that influence the perception of commercially available protein drinks. Front Nutr. (2020) 7:100. doi: 10.3389/fnut.2020.00100

Conflict of Interest: The authors declare that the research was conducted in the absence of any commercial or financial relationships that could be construed as a potential conflict of interest.

Publisher's Note: All claims expressed in this article are solely those of the authors and do not necessarily represent those of their affiliated organizations, or those of the publisher, the editors and the reviewers. Any product that may be evaluated in this article, or claim that may be made by its manufacturer, is not guaranteed or endorsed by the publisher.

Copyright $(02021$ Lampmann, Emberger-Klein and Menrad. This is an open-access article distributed under the terms of the Creative Commons Attribution License (CC $B Y)$. The use, distribution or reproduction in other forums is permitted, provided the original author(s) and the copyright owner(s) are credited and that the original publication in this journal is cited, in accordance with accepted academic practice. No use, distribution or reproduction is permitted which does not comply with these terms. 